\title{
Advanced Extracranial Malignant Solid Neoplasm
}

National Cancer Institute

\section{Source}

National Cancer Institute. Advanced Extracranial Malignant Solid Neoplasm. NCI

Thesaurus. Code C157335.

A malignant solid neoplasm that arises from any anatomic site other than the brain and has spread extensively to other anatomic sites or is no longer responding to treatment. 